\title{
A Comprehensive Survey on Machine Learning-Based Big Data Analytics for loT-Enabled Smart Healthcare System
}

\author{
Wei $\mathrm{Li}^{1} \cdot$ Yuanbo Chai ${ }^{1}$ - Fazlullah Khan ${ }^{2,3} \cdot$ Syed Rooh Ullah Jan ${ }^{4} \cdot$ Sahil Verma ${ }^{5} \cdot$ Varun G. Menon $^{6} \cdot$ Kavita $^{5}$. \\ Xingwang $\mathrm{Li}^{7}$
}

Accepted: 22 November 2020 / Published online: 6 January 2021

(C) Springer Science+Business Media, LLC, part of Springer Nature 2021

\begin{abstract}
The outbreak of chronic diseases such as COVID-19 has made a renewed call for providing urgent healthcare facilities to the citizens across the globe. The recent pandemic exposes the shortcomings of traditional healthcare system, i.e., hospitals and clinics alone are not capable to cope with this situation. One of the major technology that aids contemporary healthcare solutions is the smart and connected wearables. The advancement in Internet of Things (IoT) has enabled these wearables to collect data on an unprecedented scale. These wearables gather context-oriented information related to our physical, behavioural and psychological health. The big data generated by wearables and other healthcare devices of IoT is a challenging task to manage that can negatively affect the inference process at the decision centres. Applying big data analytics for mining information, extracting knowledge and making predictions/inferences has recently attracted significant attention. Machine learning is another area of research that has successfully been applied to solve various networking problems such as routing, traffic engineering, resource allocation, and security. Recently, we have seen a surge in the application of ML-based techniques for the improvement of various IoT applications. Although, big data analytics and machine learning are extensively researched, there is a lack of study that exclusively focus on the evolution of ML-based techniques for big data analysis in the IoT healthcare sector. In this paper, we have presented a comprehensive review on the application of machine learning techniques for big data analysis in the healthcare sector. Furthermore, strength and weaknesses of existing techniques along with various research challenges are highlighted. Our study will provide an insight for healthcare practitioners and government agencies to keep themselves well-equipped with the latest trends in ML-based big data analytics for smart healthcare.
\end{abstract}

Keywords Sensing $\cdot$ Big data $\cdot$ Data analytics $\cdot$ Internet of things $\cdot$ Healthcare $\cdot$ Machine learning

Fazlullah Khan

fazlullah@tdtu.edu.vn

1 Faculty of Engineering, Huanghe Science and Technology College, Zhengzhou, China

2 Informetrics Research Group, Ton Duc Thang University, Ho Chi Minh City 758307, Vietnam

3 Faculty of Information Technology, Ton Duc Thang University, Ho Chi Minh City 758307, Vietnam

4 Department of Computer Science, Abdul Wali Khan University Mardan, Mardan, Pakistan

5 Department of Computer Science and Engineering, Chandigarh University, Mohali, Punjab 140413, India

6 Department of Computer Science and Engineering, SCMS School of Engineering and Technology, Ernakulam 683576, India

7 School of Physics and Electronic Information Engineering, Henan Polytechnic University, Jiaozuo, Henan Province, China

\section{Introduction}

Over the years, Wireless Sensor Networks (WSNs) have experienced an unprecedented growth in terms of applications, interfacing, scalability, interoperability and data computation. These technological advances along with the innovations in Radio Frequency Identification (RFID), and wireless and cellular networks have laid a solid foundation for the Internet of Things (IoT). The term Internet of Things (IoT) was first coined by Kevin Ashton in 1999 in the context of supply chain management [1]. It refers to a smarter world of objects where every object is connected to the Internet [2]. In IoT, all these objects, also known as entities, have digital identities and are thus organized, managed and controlled remotely and thus having a scope beyond the limits. Due to the growth in the development of smart objects, IoT has enriched almost all aspects of our daily lives and is continuously doing so with diverse range of novel, innovative and intelligent applications 
$[3,4]$. These applications include smart healthcare [5], smart cities [6], smart agriculture [7], crowd sensing [8,9], and crowed sourcing [10] etc., as shown in Fig. 1.

These advancements along with innovative applications are highly encouraging and show a bright future of IoT on one side but at the same time, multiple challenges on the other side. Some of these challenges include security, big data analytics, interoperability, Quality of Service (QoS) and energy management [11]. Among them, big data is critical due to the interrelation between IoT objects and plethora of data streams generated by them. A huge amount of information is generated from a vast variety of IoT devices and applications. Various big data analytics are employed to mine such information and improve the decision making. In an IoT context, big data is classified and described by various researchers from different perspectives and various models have been proposed [12-14], however, the most prevalent among them is $5 \mathrm{~V}$ model. This model classifies the big data into five categories, based on various attributes associated with them. These attributes are, size of the data (volume), real-time data collection (velocity), heterogeneous data collection from a diverse range of resources (variety), unpredictable data (veracity), and finally the application of such data in various fields, such as industry and academia (value). Recently, we have seen a phenomenal growth in big data research due to its application in various domains. This development is further ignited by the integration of IoT with big data creating opportunities for the improvement of services for many complicated systems, such as healthcare system. In the IoT literature, there has been a large number of big data technologies that are used for the analysis of large volumes of data from a number of resources in a smart healthcare domain. Among these technologies, machine learning (ML) is a dominant technique that performs complex analysis, intelligent judgments, and creative problem solving on the big data. It is estimated that the economic impact of using ML techniques for big data analytics, i.e., ML-based products and platforms, will range from $\$ 5.2$ trillion to $\$ 6.7$ trillion per year by 2025 [15]. This signifies the importance of ML in big data, and particularly in IoT.

There exist numerous comprehensive literature reviews that recognize the research trends in big data, ML, and IoT, respectively. For instance, in [16], the authors discussed the characteristics of big data from various dimensions, i.e. volume, velocity, variety, veracity, variability and value. Moreover, they discussed the current and emerging deep learning architectures and algorithms, specifically designed for big data analytics in various IoT domains. However, the proposed review is generic because it discusses deep learning techniques for big data analysis in multiple domains. Authors in [17] studied the latest machine learning techniques for big data analytics, used for IoT traffic profiling, device identification, security, edge-enabled computing

Fig. 1 Applications of IoT

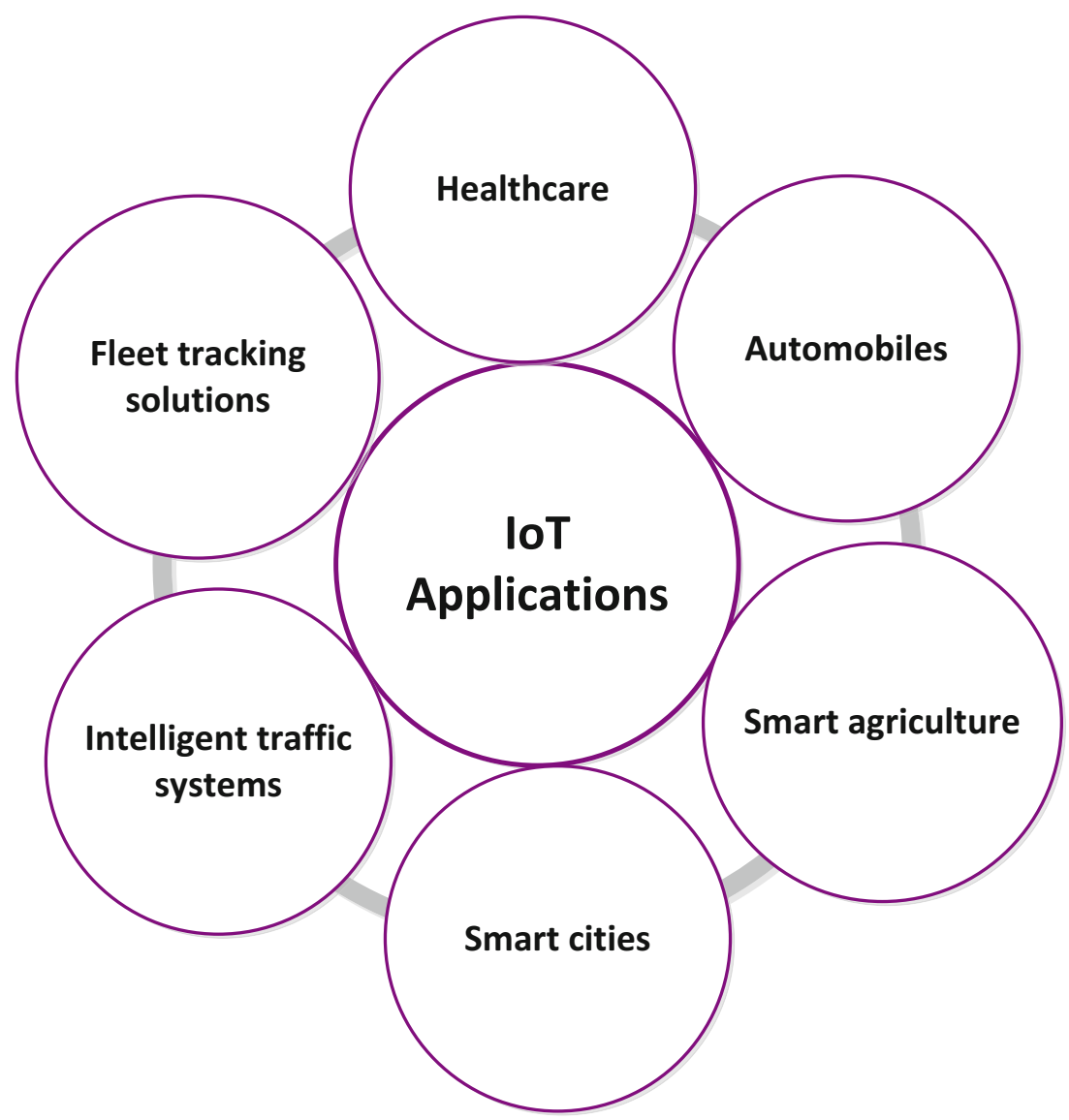


infrastructure, and network management. However, this survey is restricted to the applicability of ML techniques for big data analysis in a wide range of applications within a specific domain. Similarly, big data technologies across various sectors such as smart health, smart traffic and logistics and smart agriculture were discussed in [18]. This survey enables the readers to choose the most suitable technique from a diverse range of available techniques for data analytics across various domains. Moreover, it also studied the applicability of these techniques in cross domains. However, this survey is limited in scope and pertains only to a single domain. Besides, it partially discussed techniques from each domain. Some surveys, on the other hand, target only a single IoT domain. For instance, the authors in [19] presented a taxonomy of ML-based techniques for smart city domain. However, it does not considered security of the data and the underlying network. All these literature reviews and surveys studied big data and ML from IoT perspective for different applications such as intelligent transportation systems, smart cities, smart agriculture, crowd sensing and smart homes. However, it is evident from the literature that there is a lack of research work that exclusively investigates big data analytics and ML in IoT healthcare domain. Some of the aforementioned surveys dedicated only a single section to this topic, however, there lacks a comprehensive survey on these technologies that identify the most suitable big data technologies and ML techniques for their applicability in IoT healthcare. Moreover, studies that interlink the two cross domains, i.e., big data analytics and healthcare are still in its infancy and thus require further attention from the research community. Similarly, there is no single study that examines the significance of data aggregation and its vital role in this specific domain.

To identify these reach gaps, we have carefully reviewed various papers related to ML techniques for big data analysis. Considering the challenging aspects of big data in the IoT healthcare, in this work, our ultimate objective is to present the state-of-the-art literature on the ML techniques and big data analytics that are exclusively proposed for IoT eHealth. We have also highlighted the strength, weaknesses and future challenges in this context. This will enable the readers to choose the most suitable technique from the available pool of big data analytics tools for healthcare and explore them further in the time ahead. Based on our extensive literature review, this is the first work that targets this particular domain and thus makes it unique from the rest of the papers, available in the literature. The main contributions of this paper are as follows:

- It discusses the relationship between big data and IoT in general, followed by the state of the art big data research in IoT smart health. Finally, a comprehensive discussion is provided on various research challenges that provide further opportunities in this specific domain. This provides the most striking features to all interested parties for further exploration in the years ahead.
- Fundamental concepts of big data and the complex relationship between big data and IoT is explored.

- Big data challenges in IoT healthcare domain are discussed and future research directions are provided in this context.

- A systematic review and study of the existing data aggregation techniques, based on ML and their applicability to IoT smart health are discussed.

The rest of this paper is organized as follows. Section 2 sheds some light on the article classification and our motivation towards researching this specific domain. In Section 3, we provide an introduction of IoT by highlighting its contribution towards various applications. This section exclusively studies the recent developments and transformation of conventional healthcare sector, along with a layered architecture for Wireless Body Sensor Networks (WBSNs). Section 5 discusses the concept of big data challenges, particularly in IoT from smart healthcare perspective. Next, we provide a detailed discussion on the role of ML techniques for the analysis of big data in IoT healthcare in Section 6. A comprehensive and updated literature review on various machine learning techniques for big data analytics in IoT eHealth is provided in Section 7. Research challenges in the field are presented in Section 8. Finally, the paper concludes with Section 9 by stating the limitations and future work for further exploration. The overall structure of this paper is depicted in Fig. 2.

\section{Articles classification}

In this work, we have examined some of the well-known academic databases and publishers such as Google Scholar, ABI/INFORM Global, Academic Search Premier, Applied Science and Technology Full Text (EBSCO), ACM Digital Library, IEEE Xplore Digital Library, Science direct and general Google search engine. We have used various keywords that include but are not limited to big data, IoT and big data, big data analytics in IoT health, IoT eHealth, and machine learning and big data analytics in IoT healthcare to explore primary challenges and issues in the application of ML to big data analytics in IoT smart health. We were striving for the latest literature including journal papers, conference papers, standards, project reports, patents, white papers and reports from industries. Furthermore, we have restricted our search for the related literature that is published over the past 4 years, i.e., from 2016 to 2020. Among them, particular emphasis was given to papers related to big data research in IoT health care domain. As a result, a total of 361 papers were downloaded, however, only 90 papers among them were selected and thoroughly reviewed, as shown in the Fig. 3. Each paper was carefully analyzed to find the research gaps and clarify our research direction as well as our motivation for carrying out this research. Based on our result, we have selected only 7 out 


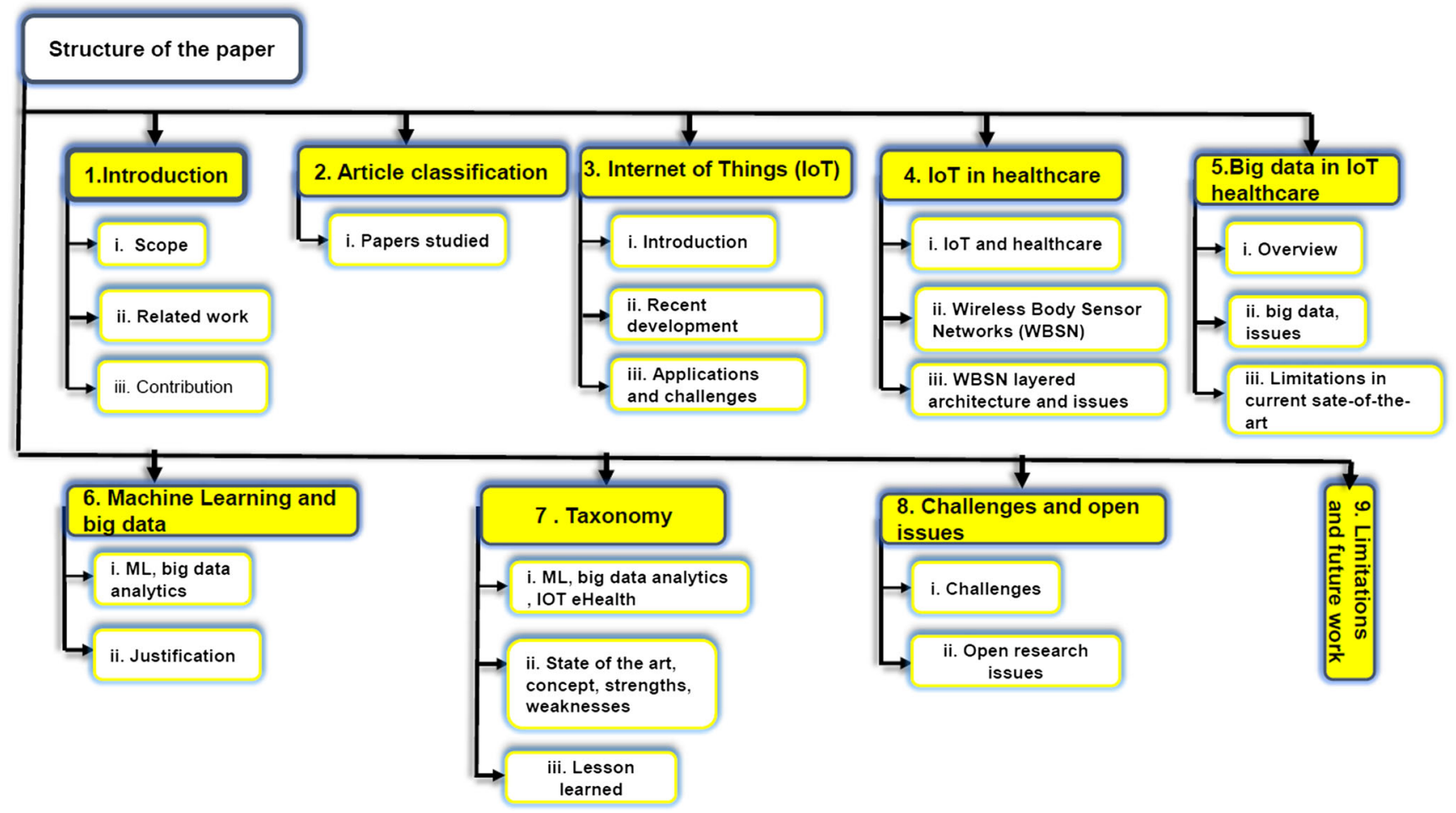

Fig. 2 Structure of the paper

of all research papers, which are [18, 20-25]. A detail discussion on these survey papers was provided in Section 1 that justify as to why we have carried out this research work, and our motivation behind this paper. Moreover, strengths and weaknesses of the aforementioned papers are also provided to justify our work along with the contributions and novelty of this survey.

\section{The internet of things}

IoT is a web of smart and self-configuring things that can communicate with each other using a global network. It is essentially cyber-physical systems or a network of networks. An informal description for the phrase "IoT" was put forth by IEEE, as "a network of objects each of which is embedded
Fig. 3 Relevant Articles Published over the time

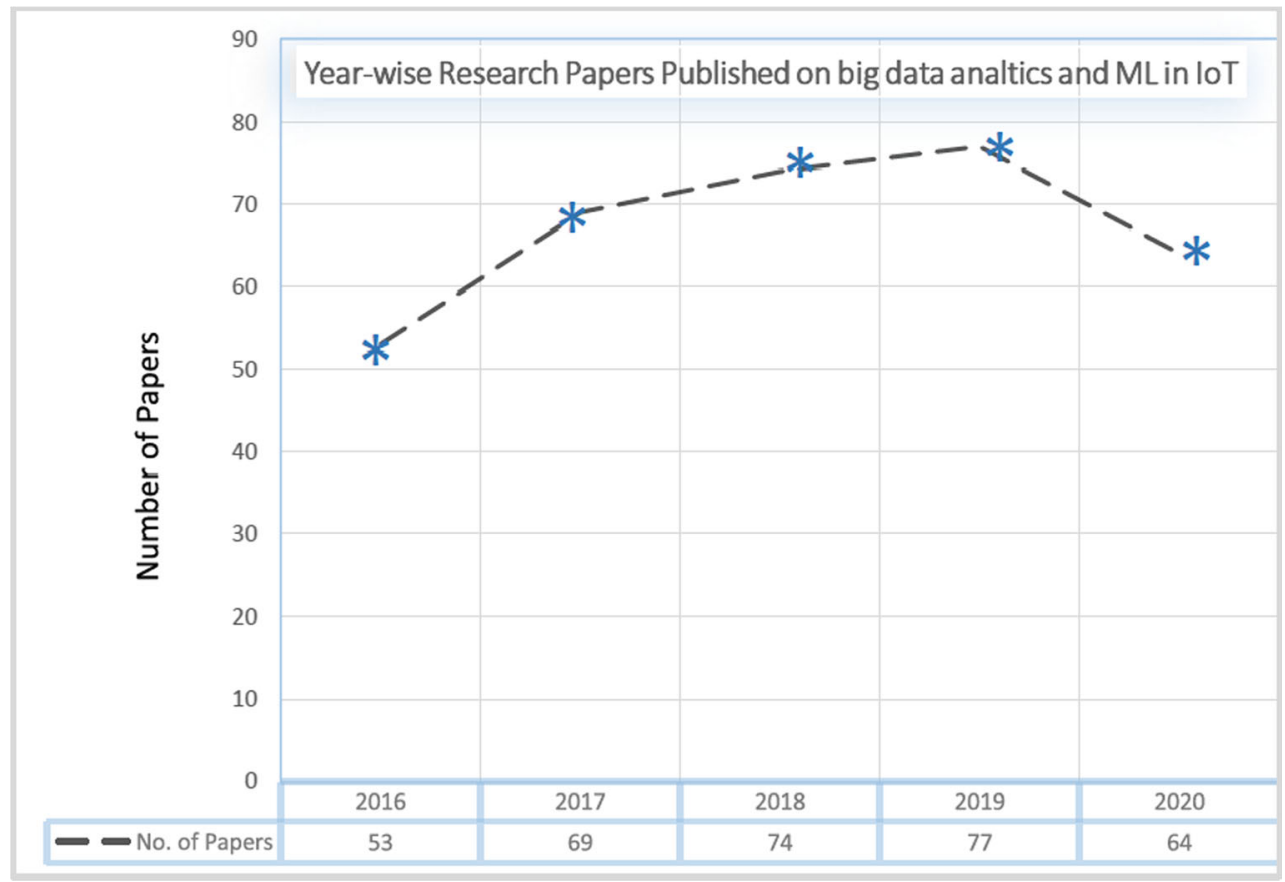


with sensors and these sensors are connected to the Internet" [26]. The seamless communication among participating objects is facilitated using the low-cost sensors installed into a diverse range of objects supporting ubiquitous and pervasive computing applications [27]. Apart from these, other technologies that further stimulated the development of the IoT are wireless technologies, micro-electro-mechanical systems (MEMS) and the Internet. According to the market analysts, around 25 billion sensor-enabled devices will be installed by 2020 [28]. Moreover, the market scope of such devices is expected to be around 2.1 trillion by 2025 [29]. This implies that billions of physical devices or sensor-enabled objects will be connected and will communicate with each other via the Internet. The plethora of objects will generate huge and in most cases, real-time heterogeneous and complex data. It is therefore imperative to extract useful patterns from these raw data in an efficient manner. The raw data gathered from the physical environment need to be analyzed and mined for novel feature extraction and useful information. This become particularly important with the evolution of intelligent IoT applications, where the devices communicate with each other and enable them to share information by making intelligent decisions. As a result, big data analytics using data mining techniques is evolving as a new area of research. In recent years, we have witnessed the development and deployment of a large number of IoT applications [30-32]. These applications include smart cities, smart energy management, smart agriculture, military applications, environmental monitoring and healthcare. IoT has the capabilities to refurbish the current and future scenario of healthcare sector with promising technological, economic, and social prospects. It is estimated that the economic impact of IoT-enabled hardware and software will reach USD 176.82 Billion by 2026 [33]. The healthcare sector alone will constitute about $41 \%$, a major share followed by industrial automation with $33 \%$ and energy with $7 \%$ of the IoT market [34]. Apart from these, $15 \%$ of the IoT market is related to objects and product-related transportation, agriculture, urban infrastructure, security, and retail sectors. These outlooks indicate the remarkable growth of the IoT services to healthcare industry on one side, while, challenges such as big data and other challenges on the other side that the research community will face shortly.

\section{4 loT in healthcare}

With the emergence of eHealth and mHealth, we have witnessed an increasing role of technologies in the healthcare sector. Millions of sensors are attached to the patients that continuously monitor their health using various physiological, environmental and behavioural parameters. In healthcare IoT, i.e., eHealth and mHealth, wireless body sensor networks (WBSN) is a predominant technology for monitoring the

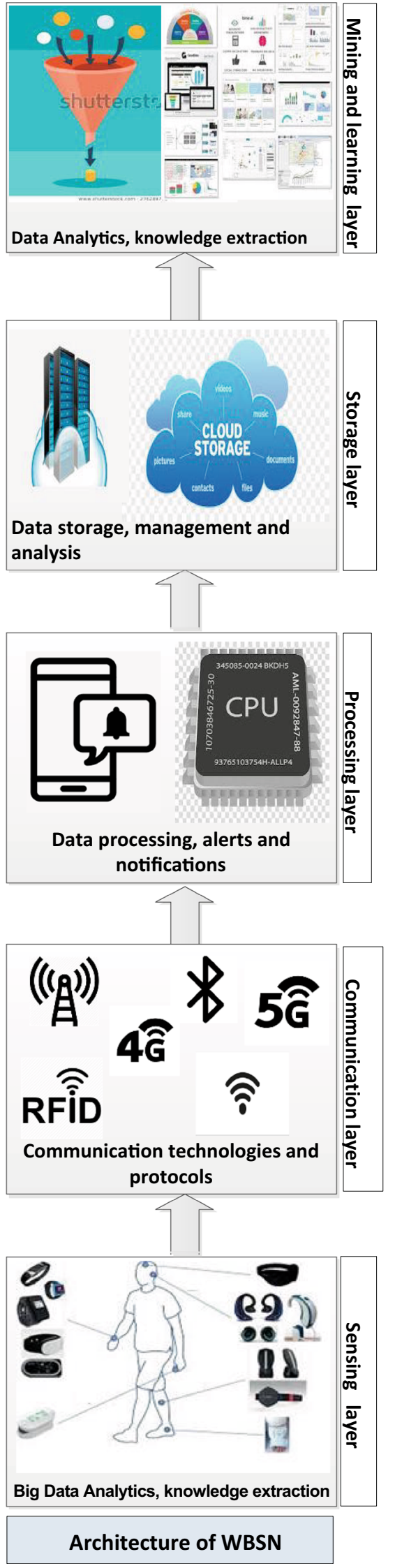

Fig. 4 Layered Architecture of Wireless Body Sensor Network 
patients. WBSN consists of sensors that are deployed around the human body [35]. The layered architecture of WBSN comprises of sensing layer, communication layer, processing layer, storage layer, and mining and learning layer as shown in Fig. 4 [36]. Each layer contains various components with their responsibilities. The sensing layer includes various sensing devices, such as wearable sensors and in-body sensors. Recently, medical super sensors (MSS) came into the market that have more memory with improved processing and communication capabilities as compared to the ordinary sensor nodes. These sensors are usually wearables or sometimes implanted inside the patients' skin and can communicate with the network. These sensors gather vital information pertaining to body temperature, blood pressure, heartbeat rate, respiration rate, ECG, and blood glucose for diabetic patients [37]. In recent years, actuators are employed for raising alarms and modifying the environmental parameters, whenever necessary. We have witnessed huge developments in these applications in the form of novel monitoring applications. As a result, a large amount of contextual data is generated from these applications. It is mandatory to consider big data among other challenging issues while designing devices at the sensing layer. Some of these issues are price, size, energy consumption, memory, processing, power, deployment and organization of various devices at this layer. The next layer is the communication layer which is somehow similar to physical layer of the TCP/IP model. This layer is responsible for physical objects to connect and share data in WBSN, using specific communication protocols. It facilitates the inter and intra network communication. Standard and communication protocols defined at this layer provides interoperability in WBSN. These protocols also facilitate the exchange of data with existing infrastructures. There are various standards used by WSBN for intra communication at this layer, such as Bluetooth, ZigBee, RFID, NFC and UWB [38-40]. Each of these standards have their pros and cons and are used based on the specific application's requirements [41]. Various challenges faced at this layer are network management, QoS (congestion, latency and energy efficiency), and security and privacy. Apart from these, data aggregation and big data analytics need to be considered for further exploration. These techniques preserve energy of the resource starving networks by substantially lowering the data transmission across the network. The third layer is the processing layer that analyzes the gathered data, makes decisions, and raises alarms and notifications. The main components of this layer are: (a) the processing unit (b) hardware platforms, and (c) operating system. The challenging issue at this layer is the limited processing capabilities of hardware components. The partially analyzed data at this layer is then passed on to the next layer, i.e., the Storage Layer. In IoT healthcare, a large number of devices can be attached to the human body that generates massive and complex data. It is the responsibility of storage layer to efficiently manage and store such data for further analysis and usage. IoT-based system are low on memory and are therefore unable to store such data. To overcome this limitation, numerous cloud-based platforms are available for the storage of data such as ThingWorx [41], OpenIoT [26, 42], Google Cloud [43], Amazon [44], Nimbits [45], GENI [46, 47]. These platforms improve the management and storage of data. Data can be reviewed and accessed virtually from anywhere and everywhere. This in turn facilitates the health professionals and researches to explore it further for better understanding and advancement of the field. Finally, the mining and learning layer is responsible for big data analytics and knowledge extraction. Various data mining techniques are available in the literature, however, ML techniques are successfully applied for big data analytics in health care IoT $[17,48]$. ML-based techniques can manage huge data set efficiently, learn from the data and improve the learning experience. They are used to mine the vast amount of medical information and extract useful, potentially interesting, and unique and hidden information. The main components of this layer are: clustering, classification, association analysis, time series analysis, and outlier analysis [19, 49]. It is expected in the future that feedback will emerge from this layer, as opposed to present IoT scenario, where it comes from the clinics.

\section{Big data challenges in loT smart healthcare}

Despite the hype surrounding the smart applications of eHealth and mHealth in IoT, big data is still a challenging issue. Sensors and various medical devices attached to the patients' bodies generate massive volumes of heterogeneous data, also called Big Data [50]. This huge volume of data contains highly correlated and redundant patterns. It is imperative to mine these data for providing continuous, efficient, and seamless healthcare facilities around the clock. However, the challenging issues are the processing and transmission of such data across the network. These issues not only consume higher energy but also bandwidth of the resource-constrained networks that lead to congestion and reduces the energy and lifetime of the underlying networks [51]. It is therefore imperative to aggregate raw data, using big data analytics, before transmitting it across the network for accurate and timely decision making. Moreover, it becomes a major concern for all stakeholders to process the data within the network intelligently and efficiently. Removing redundant and erroneous data, while identifying and extracting meaningful information and gaining new insights into the large volume of raw captured data is the core utility of big data analytics [52]. These techniques not only improve the performance but also conserve the energy using novel energy management techniques by enabling the long term operation of these networks [20, 51, 53]. 


\section{Machine learning and big data analytics for loT}

In this section, we discuss the application of ML for big data analytics. ML is a subfield of computer science that evolved from pattern recognition and computational learning theory [54]. It is a type of Artificial Intelligence (AI) that provides machines with the ability to learn without explicit programming by making complex decisions [55]. In the past, it has been successfully applied to various domains such as computer vision [56], computer graphics [57], natural language processing (NLP) [58], speech recognition [59], computer networks [60], and intelligent control [61]. In recent years, we have witnessed its vital role in IoT and big data analytics due to its phenomenal growth with a diverse range of innovative applications. As a result, highly correlated data is produced from these heterogeneous and complex data sources, i.e., IoT devices. Thus, data management in these systems becomes extremely difficult that results in numerous challenges for the research community [62-65]. It is important to manage data from these large number of sources with increased velocity and scalability by devising novel big data analysis techniques. Existing techniques are ineffective due to lower accuracy and higher energy consumption that does not cater to these diverse ranges of applications. It is necessary to improve these techniques to cater to various applications. ML techniques play a pivotal role in IoT eHealth [66]. It empowers us to obtain deep analytics from a larger pool of available information. It mines useful information and features hidden in IoT data, and facilitates the decision-making process. Moreover, it helps us in the development of efficient and intelligent IoT applications. An IoT analysis model consists of various components such as data sources, edge/fog computing, and ML techniques for IoT big data analytics. In this model, the potential data sources include wearable devices such as sensors, and body area networks. They capture information related to human health such as temperature, ECG, and environmental data like humidity and camera's images. Various ML techniques are applied to the data captured by these sources for further analysis. It is evident from the literature that ML techniques have successfully been applied for big data analysis in various applications of IoT such as smart traffic [67, 68], smart agriculture [69], smart human activity control [70], smart weather prediction [16, 71], healthcare [72, 73], and smart cities [19]. Big data has been studied in a diverse range of IoT domains. However, it is evident from the literature that there is lack of a comprehensive literature review that exclusively investigates big data analytics in IoT healthcare. Though, some of the aforementioned surveys dedicated only a section to this domain, there is no single study that examines the significance of ML techniques for big data analysis in IoT healthcare. In the next section, we present state-of-the-art literature by reviewing the latest ML techniques for big data analysis in IoT smart healthcare system. Moreover, strengths and weaknesses along with future challenges are also highlighted. This provides an insight to the readers that enable them to explore it further in the future.

\section{A taxonomy of machine learning techniques for big data analysis in loT smart healthcare system}

IoT aims to improve the quality of human lives by automating some of the basic tasks that otherwise humans need to perform manually. In this context, monitoring and decision making is shifted from humans to machines. For instance, in IoT-based assisted living applications, sensors are attached to the health monitoring unit used by the patients. The information gathered by these sensors are transmitted across the network and are made available to all interested parties. This not only helps in timely treatment of the patients but also improves the responsiveness and accuracy of the underlying application $[74$, 75]. Moreover, the current medicines taken by the patient are monitored and the risk of new medication is evaluated in terms of any allergic reaction $[66,76]$. As a result, not only the time is conserved but monetary value remains in place too. In this section, we review only selected ML techniques for big data analytics in IoT eHealth. Moreover, the key concepts along with their similarities and differences, strength and weaknesses are provided, and are summarized in Table 1.

\subsection{ML-based recommendation system}

In [77], the authors proposed a recommendation system that devised the most feasible IoT wearable devices, based on the needs of an individual. The proposed system initially gathers the available data related to a patient's health, e.g., previous history, demographic information, and retrieval of archived data from the sensors attached to the patient. Various MLbased classification techniques such as decision tree, logistic regression and LibSVM, are used to predict the occurrence of diseases. Finally, a mathematical model is used for recommending a customized IoT solution for each individual. In [78], the authors proposed a disease prediction system by performing the real-time Electrocardiograph (ECG) analysis. Firstly, the proposed approach analyzes and classifies the ECG waveforms that are captured in real-time from the ECG monitoring devices using various ML classifiers such as KNN and bagged tree. Next, any signs of diseases and abnormalities in the ECG are predicted and are then communicated to the cloud in real-time via a purpose-built IoT network, owned by the National Health Services (NHS), UK. Simulation results showed that the precision of the proposed scheme can reach up to $99.4 \%$. However, the precision as well as the 
Table 1 Key technological concepts, their similarities and differences

Category Description

Big data and their characteristics [16]

Machine learning, big data analytics in diverse range of applications [17]

Machine learning techniques for big data analysis in smart cities domain [19]

Big data analytics in various IoT application domains [18]

Provides a systematic review of the latest data

Aggregation techniques for IoT [21]

Challenges facing IoT [23]

Data redundancy in IoT sensor networks [22]

Applications of machine learning for big data analytics in IoT domain [17]. issues. provided.
Discuss IoT from the big data perspective. Also discusses the characteristics of big data from the $6 \mathrm{Vs}$ dimensions, i.e. Volume, Velocity, Variety, Veracity, Variability and Value. Also, analyze and summarize major research attempts that apply deep learning in the IoT domain. Finally, it shed light on some challenges and potential directions for future research in this area.

Focuses on the application of machine learning for IoT followed by the relevant techniques, including traffic profiling, IoT device identification, security, edge computing infrastructure, network management and typical IoT applications. Also highlight the most recent advances in machine learning techniques and their diverse applications, challenges and open

Use case of applying modified Support Vector Machine (SVM) to Aarhus smart city traffic data. Also, present a taxonomy of machine learning algorithms. It further explains the application of these techniques to big data analytics in smart cities domain. The paper is finally concluded with research challenges, and future research directions.

Discuss, analyze and divide latest research related to big data analysis in various IoT application domains. It guides the readers to choose the most suitable technique from a diverse range of available techniques for big data analytics in these domains. A critical view of various big data technologies across these categories are also presented.

Classify data aggregation techniques based on their underlying topologies, such as, tree, cluster and centralized. It also explores various challenges that these techniques face. A discussion on various performance metrics such as energy efficiency and latency is also provided for the accurate evaluation of these techniques. A comparative study along with their strength and weaknesses of these techniques as well as recommendations for further extension in the future is

This paper discusses a wide range of technology-based issues and challenges facing IoT. It further explains the vision and various features of this paradigm from different dimensions. The key feature of this work is that it provides a comprehensive and latest survey on a diverse range of IoT enabling emerging technologies. Moreover, It also classifies the existing literature based on different research topics. Finally, an insight into various research challenges and research issues are also provided for further research in the field.

This paper reviews the challenging aspect of data redundancy and recommends data aggregation as an effectively technique to overcome on this issue. It present cluster based data aggregation techniques. It also classify these techniques based on the location of deployment, their pros and cons and future challenges.

This highlight the application of machine learning technique (supervised and unsupervised) for big data analytics in various application domains. It thoroughly discusses security techniques related to device security and network security. In the end, a comprehensive discussion is provided on various challenges and open research issues. 
performance need to be evaluated using other metrics such as time complexity and energy efficiency.

In [79], the authors proposed an IoT architecture having five distant but inter-related layers. The first layer is the sensing layer, which includes various sensing devices used for gathering the data. These devices include but are not limited to, sensors, actuators, and a wide range of wearable devices. The second layer is the sending layer, which is somehow similar to the physical layer of the Open Source Interconnection (OSI) model. Its main responsibility is to devise various communication mechanisms for data transmission. This layer discusses communication mechanisms such as Wi-Fi, Bluetooth, ZigBee and Long Term Evolution (LTE) for sending the data to cloud. The third layer is the processing layer, which is concerned with the processing of data, based on some pre-defined criteria. Once the data is processed, notifications and alerts are generated in response. Some of the devices where processing occurs are smart phones, microcontrollers and microprocessors. At the fourth layer, i.e., storage layer, the data is stored at a preferred location such as clouds and hosted servers. Finally, the fifth layer, also known as the mining layer, converts the information into decisions using a diverse range of data mining or ML algorithms for reaching a conclusion. Based on the decision, various suggestions and recommendations are made. In [80], the authors proposed a recommender system Pro-Trip, which allows the users to organize the activities before a trip or on an ongoing trip. Pro-Trip collects all the data from the patients that is used for further recommendations to provide accurate results. The authors also proposed a technique for food RS designed for the healthcare system. The results of Pro-Trip are evaluated based on climate and food datasets that are collected in real-time. In the food recommendation system, they have evaluated the performance with latency, energy efficiency, and security in mind. In [81], the authors proposed a novel recommendation system based on Type- 2 fuzzy ontology-aided RS, especially designed for IoT-based healthcare systems. It overcomes the issues faced while monitoring and extracting the optimal value of risk factors in patient's data. Hence, the proposed technique ensures to observe the patient and then recommends the diet with a discrete amount of food and medicines. This approach evaluates the risk faced by the patient, deduces the health state of the patient with the help of wearable devices embedded with sensors, and further suggests the prescription of medicines and food. Authors have amalgamated two techniques: Type-2 fuzzy logic and fuzzy ontology, which remarkably improve the rate of prediction of recommendation. The accuracy, recall, and precision are compared with other ontologies, i.e., Type-1 and classical, which show excellence in the results. The future work could magnify upon the Type-2 fuzzy neural network and sentiment analysis for the RS. In Table 2, we have shown various recommendation systems for smart healthcare.

\subsection{ML-based prediction system}

In [82], the authors proposed an IoT framework for predicting whether the person under observation is in stress or not by monitoring his/her heart beats. The proposed framework detects the pulse waveforms using a specially designed $\mathrm{WiFi}$ equipped board, which forwards the data to a pre-defined server. Next, the data gathered at different time intervals are assembled and stress prediction is evaluated by applying various ML techniques such as SVM and logistic regression. Simulation results showed that precision of the proposed framework can reach up to $68 \%$. However, its precision can be improved further using appropriate classification models. In [83], the authors proposed a smart tele-health monitoring system using speech recognition algorithms. Its design goal is to identify and predict the occurrence of Parkinson's disease using K-mean algorithm. The proposed system is deviceindependent and can be employed by a variety of wearable devices. The proposed system employs an edge computing framework as the wearable devices are resource-limited. The idea behind using edge computing is to achieve distributed services by reducing the reliance on centralized infrastructure. In [84], a cloud-based IoT framework was proposed for monitoring various diseases. It forecasts the level of these diseases, i.e., from normal to severe among students. It utilizes the concept of computational science on the data collected from the students using sensors and are stored at a repository to predict severity of the disease. Furthermore, various classification algorithms are used to predict the occurrence of such diseases. The proposed approach is evaluated using various performance metrics such as specificity, sensitivity, and F-measure. Simulation results prove that in terms of accuracy, the proposed approach outperforms the traditional approaches. In [85], the authors proposed a smart e-Health Gateway at the edge of the network in Fog-assisted system architecture. The gateway can perform real-time data processing, data mining, and data storage, locally. Moreover, the strength of the proposed architecture is that it can enable us to solve some of the emerging and complex issues faced by the ubiquitous healthcare systems, such as mobility, energy efficiency, scalability, and reliability. Practical demonstration of proposed prototype demonstrated high-level features such as Early Warning Score (EWS) of our health monitoring system. The authors in [86] proposed a three-layer architecture for storing a large amount of sensory data for earlier prediction of heart diseases. In the proposed architecture, the first layer is responsible for data collection. The second layer is concerned with the storage of large volume of sensory data at the cloud. Finally, in the third layer, a prediction model for heart diseases is developed. At this layer, "Receiver Operating Characteristic Curve (ROC) analysis is performed that identifies potential symptoms before the occurrence of heart disease. In [87], the authors discussed the application of IoT in healthcare. They presented a novel 
Table 2 ML-based Recommendation Systems for Smart Healthcare

\begin{tabular}{|c|c|c|c|c|}
\hline Description & Features & Type & Strengths & Weaknesses \\
\hline $\begin{array}{l}\text { Recommend the } \\
\text { most feasible } \\
\text { wearable based on } \\
\text { the needs of an } \\
\text { individual. [77] }\end{array}$ & $\begin{array}{l}\text { Patient's health, for e.g., } \\
\text { previous history, } \\
\text { demographic information, } \\
\text { and retrieval of archived } \\
\text { data }\end{array}$ & $\begin{array}{l}\text { Recommendation } \\
\text { System }\end{array}$ & Efficiency & $\begin{array}{l}\text { lacks numerical } \\
\text { analysis }\end{array}$ \\
\hline $\begin{array}{l}\text { Diseases prediction } \\
\text { system to perform } \\
\text { real time } \\
\text { Electrocardiograph } \\
{[78]}\end{array}$ & $\begin{array}{l}\text { Cardiac abnormalities in } \\
\text { real-time }\end{array}$ & $\begin{array}{l}\text { Recommendation } \\
\text { System }\end{array}$ & Accuracy & $\begin{array}{l}\text { Portability, } \\
\text { real-time } \\
\text { Monitoring }\end{array}$ \\
\hline $\begin{array}{l}\text { IoT architecture } \\
\text { having five distant } \\
\text { but inter-related } \\
\text { layers [79] }\end{array}$ & $\begin{array}{l}\text { Layer1: Sensing layer } \\
\text { Layer2: Sending layer } \\
\text { Layer3: Processing layer } \\
\text { Layer4: Storage layer } \\
\text { Layer5: Mining layer }\end{array}$ & $\begin{array}{l}\text { Recommendation } \\
\text { System }\end{array}$ & Accuracy & $\begin{array}{l}\text { Quite complex } \\
\text { system }\end{array}$ \\
\hline $\begin{array}{c}\text { Recommender } \\
\text { system Pro-Trip } \\
{[80]}\end{array}$ & $\begin{array}{l}\text { Allows the users to organize } \\
\text { the activities before a trip } \\
\text { or on an ongoing trip }\end{array}$ & $\begin{array}{l}\text { Recommendation } \\
\text { System }\end{array}$ & Accuracy & $\begin{array}{l}\text { Results of } \\
\text { Pro-Trip are } \\
\text { evaluated } \\
\text { based on cli- } \\
\text { mate and food } \\
\text { datasets }\end{array}$ \\
\hline $\begin{array}{l}\text { Type-2 fuzzy } \\
\text { ontology-aided } \\
\text { RS, designed for } \\
\text { IoT-based } \\
\text { healthcare systems }\end{array}$ & $\begin{array}{l}\text { The proposed technique } \\
\text { ensures to observe the } \\
\text { patient and then } \\
\text { recommends the diet with } \\
\text { a discrete amount of food } \\
\text { and medicines and } \\
\text { evaluates the risk faced by } \\
\text { the patient, deduces the } \\
\text { health state of the patient. }\end{array}$ & $\begin{array}{l}\text { Recommendation } \\
\text { System }\end{array}$ & Accuracy & $\begin{array}{l}\text { Lack of } \\
\text { sentiment } \\
\text { analysis for the } \\
\text { RS. }\end{array}$ \\
\hline
\end{tabular}

ML-based model for disease classification in a healthcare monitoring system. Based on the extensive simulations, it was concluded that the proposed framework can extensively enhance the performance and detects diseases with higher accuracy. In [88], the authors proposed a Hierarchical Computing Architecture (HiCH) for the IoT healthcare sector. They proposed and implemented a system, similar to IBM's MAPE-K model REF for the arrhythmia detection. The proposed system has three distant but interrelated layers of fog computing. They are: sensor devices layer, edge computing devices layer, and cloud computing layer. The responsibility of the first layer, i.e., sensor devices layer, is to sense and monitor the phenomenon of interest. Next, edge computing devices layer is responsible for making a local decision as well as system management. Finally, heavy training procedures are performed at the cloud layer. Simulation results show that the proposed system outperforms the traditional systems in terms of response time, bandwidth utilization, and memory utilization. However, accuracy of the proposed system is lower and may be improved further in the future. In [89], the authors proposed a low-cost, remote monitoring system that detects various fatal diseases such as cardiovascular diseases, diabetic mellitus, hypertension and different chronic degenerative medical conditions. The proposed system detects these diseases by measuring Heart Rate Variability (HRV), i.e., variation that occurs between consecutive heart beats concerning time. The data from the patients are captured using Zigbee pulse sensor. The captured data is then transmitted to the application server using Message Queuing Telemetry (MQTT), a specially designed IoT protocol. At the application server, the HRV data is further analyzed and visualized that shows any abnormalities for timely actions to be taken. Similarly, in [90], a novel, intelligent system called neuro-fuzzy temporal intelligent medical diagnosis system was proposed. The proposed system uses fuzzy rules that can classify and efficiently predict various fatal diseases. In Table 3, we have shown various MLbased prediction systems for smart healthcare.

\subsection{ML-based data aggregation}

The authors in [91] proposed a real-time data compression technique, known as Adaptive Learner Vector Quantization (ALVQ). The unique feature of ALVQ is that it works without having prior knowledge of the underlying topology. Initially, data is aggregated at the sensor level by wearables to ensure that only non-correlated data is forwarded towards the cluster 
Table 3 ML-based Prediction Systems for Smart Healthcare

\begin{tabular}{|c|c|c|c|c|}
\hline Description & Features & Type & Strengths & Weaknesses \\
\hline $\begin{array}{c}\text { Remote monitoring } \\
\text { system for } \\
\text { cardiovascular } \\
\text { activities [89] }\end{array}$ & $\begin{array}{l}\text { Detection of fatal } \\
\text { diseases }\end{array}$ & $\begin{array}{r}\text { Prediction } \\
\text { System }\end{array}$ & $\begin{array}{l}\text { Low-cost, secured, } \\
\text { quick, easy-to-use }\end{array}$ & $\begin{array}{l}\text { Interoperability } \\
\text { with the web, low } \\
\text { memory }\end{array}$ \\
\hline $\begin{array}{l}\text { Low-cost heart } \\
\text { monitoring system [82] }\end{array}$ & $\begin{array}{l}\text { Cardiovascular } \\
\text { stress prediction } \\
\text { using SVM }\end{array}$ & $\begin{array}{r}\text { Prediction } \\
\text { System }\end{array}$ & Utility, Accuracy & Efficiency, Privacy \\
\hline $\begin{array}{l}\text { Smart telehealth system } \\
\text { using speech } \\
\text { recognition. [83] }\end{array}$ & Parkinson & $\begin{array}{r}\text { Prediction } \\
\text { System }\end{array}$ & $\begin{array}{l}\text { Lightweight, } \\
\text { Energy-efficient }\end{array}$ & $\begin{array}{l}\text { Security, } \\
\text { Effectiveness }\end{array}$ \\
\hline $\begin{array}{c}\text { ROC-based 3-tier predic- } \\
\text { tion model for heart } \\
\text { diseases [86] }\end{array}$ & Cardiovascular & $\begin{array}{r}\text { Prediction } \\
\text { System }\end{array}$ & $\begin{array}{l}\text { Scalable, } \\
\text { availability, high } \\
\text { throughput }\end{array}$ & $\begin{array}{l}\text { Energy-efficiency, } \\
\text { Accuracy }\end{array}$ \\
\hline $\begin{array}{l}\text { IBM-based MAPE-K for } \\
\text { disease detection. [88] }\end{array}$ & Arrhythmia & $\begin{array}{r}\text { Prediction } \\
\text { System }\end{array}$ & $\begin{array}{l}\text { Response-time, } \\
\text { Bandwidth, } \\
\text { Memory } \\
\text { utilization, }\end{array}$ & Accuracy, \\
\hline $\begin{array}{c}\text { Fuzzy-enabled Intelligent } \\
\text { medical diagnosis } \\
\text { system [90] }\end{array}$ & Nervous system & $\begin{array}{r}\text { Prediction } \\
\text { System }\end{array}$ & Efficient & Accuracy \\
\hline
\end{tabular}

head $(\mathrm{CH})$. This not only reduces the computational cost on the $\mathrm{CH}$ but also reduces communication cost in the network. However, the proposed technique does not devise any aggregation mechanism at the $\mathrm{CH}$ level. Moreover, the applicability of this technique should be evaluated for critical applications with an acceptable level of accuracy. In [92], the authors presented a cluster based self-Organizing data aggregation framework for a healthcare facilitation. A self organizing algorithm is employed that classifies the aggregated healthcare data. The proposed scheme reduces the high-dimensional space into low-dimensional space that lowers the amount of transmitted data in the network and enhances the network lifetime. Moreover, it also enhances the quality of the aggregated data. In [93], the authors eliminated the highly correlated data using big data techniques. Hadoop framework was used to extract the critical information from data captured by sensors detached with the patients. Once redundancy is eliminated, the refined data is forwarded towards the physicians in real-time for timely action. As a result, various services provided by health care professionals are significantly improved. This reduces the amount of data transmitted across the network that in turn improves the responsiveness, accuracy, QoS, energy conservation and network lifetime. In [94], a novel framework known as "health informatics processing pipeline" for big data analytics in IoT was proposed. The proposed framework uses various techniques to extract useful patterns from the raw gathered data. The main features of the proposed framework include data capturing, storage, analysis, and data searching. The proposed framework eliminates the correlated data and transmits only highly refined and useful features. These features enable the framework to decide with the help of a decision support system using various ML techniques. In Table 4, we have shown various ML-based data aggregation schemes for smart healthcare.

\subsection{ML-based living assistance}

IoT-based solutions are assisting elderly population in the form of personalized, preventive and collaborative care. In this regard, authors in [95] presented IoT-based living assistance for the aged population. The proposed system monitors and stores the vital information of patients using a cloudconnected wrist band. An alarm is raised during critical situations that assist the patients by informing the healthcare professionals to take the right action and decision. The proposed solution is both energy and cost-efficient. Likewise, in [96], the authors proposed a framework that monitors medicine intake of patients. The key attributes of the proposed system are that: it tracks the medicine intake from the patients history including missed dosage. In case of medication discrepancy, such as missed or over dosage, an alarm is generated alerting both the patients as well as the medical staff. Moreover, in [97], authors designed a patient monitoring system for critically ill patients in the intensive care unit (ICU). The proposed system informs and assists all stakeholders in real time, whenever abrupt changes occurs in the pre-defined conditions for timely action. In [98], the authors has proposed a novel monitoring system based on the patient movement. The proposed system provides emergency services to the patients by evaluating their emergency situation from monitoring their movement. The in-home patient monitoring system relies especially on the proposed monitoring system. In [99], a system that explicitly detects the human presence without using cameras or motion detectors was proposed. Initially, the system 
Table 4 ML-based Data Aggregation for Smart Healthcare

\begin{tabular}{|c|c|c|c|c|}
\hline Description & Features & Type & Strengths & Weaknesses \\
\hline $\begin{array}{l}\text { Real-time data, } \\
\text { Compression using } \\
\text { Adaptive-learner } \\
\text { Vector quantization } \\
{[91]}\end{array}$ & $\begin{array}{l}\text { It works without } \\
\text { having prior } \\
\text { knowledge of the } \\
\text { underlying } \\
\text { topology. }\end{array}$ & $\begin{array}{l}\text { Data } \\
\quad \text { aggrega- } \\
\text { tion }\end{array}$ & $\begin{array}{l}\text { Compression, } \\
\text { Efficiency, signal } \\
\text { reconstruction, }\end{array}$ & $\begin{array}{l}\text { Ignore } \\
\text { multidimensional } \\
\text { data, Missing } \\
\text { data }\end{array}$ \\
\hline $\begin{array}{c}\text { Self-organizing approach } \\
\text { to transform high } \\
\text { dimensional space into } \\
\text { low dimensional space. } \\
{[92]}\end{array}$ & $\begin{array}{l}\text { It enhances the } \\
\text { quality of the } \\
\text { aggregated data }\end{array}$ & $\begin{array}{l}\text { Data } \\
\quad \text { aggrega- } \\
\text { tion }\end{array}$ & $\begin{array}{l}\text { Reliability, } \\
\text { Efficiency, } \\
\text { Communication } \\
\text { cost }\end{array}$ & $\begin{array}{l}\text { Fault tolerance, } \\
\text { Topological } \\
\text { support }\end{array}$ \\
\hline $\begin{array}{l}\text { Hadoop-based } \\
\text { framework for } \\
\text { spatially and } \\
\text { temporally correlated } \\
\text { data elimination [93] }\end{array}$ & $\begin{array}{l}\text { Improves the } \\
\text { responsiveness, } \\
\text { accuracy, QoS, } \\
\text { energy } \\
\text { conservation and } \\
\text { network lifetime. }\end{array}$ & $\begin{array}{l}\text { Data } \\
\text { aggrega- } \\
\text { tion }\end{array}$ & Energy-conservation & $\begin{array}{l}\text { Flexibility, } \\
\text { Efficiency }\end{array}$ \\
\hline $\begin{array}{l}\text { Health informatics } \\
\text { framework for } \\
\text { gathering, storing, } \\
\text { analysing, and } \\
\text { searching data for } \\
\text { accurate decisions. } \\
\text { [94] }\end{array}$ & $\begin{array}{l}\text { It includes data } \\
\text { capturing, } \\
\text { storage, analysis, } \\
\text { and data } \\
\text { searching. }\end{array}$ & $\begin{array}{l}\text { Data } \\
\text { aggrega- } \\
\text { tion }\end{array}$ & Accuracy & Optimization \\
\hline
\end{tabular}

collects interactive data, i.e., reading or writing with a diverse range of devices. Next, the presence of human is detected using various ML classification algorithms such as C4.5 decision tree, linear SVC and random forest. The system was initially trained and tested using a dataset gathered over a period of 3 days from 900 users. Simulation results shows that the precision of the proposed approach may vary from 50 to $99 \%$ with varying range of classification algorithms. However, it needs to be tested in real world scenarios within various settings to study its behaviour. In [100], the authors proposed an inexpensive health-care monitoring system for patients. The model is based on lightweight sensor-enabled wearable devices performing sensing, analyzing and sharing of real-time health-care data from the patients. An Arduinobased wearable device with body sensor networks is employed for data collection. Moreover, Labview is integrated with the system to facilitate the remote monitoring of home-bound patients. The proposed system eliminates many deficiencies that exist in manual systems. In Table 5, we have shown various ML-based assisted living approaches for smart healthcare.

\subsection{ML-based secured analysis}

It is imperative to ensure the security and privacy of health care data due to its sensitive nature. In this regard, authors in [101] presented an on-line healthcare monitoring system. The proposed system collects and analyzes the health-related data from the patients, using sensors and medical devices, that negate the death circumstances. They fused various techniques such as watermarking and signal enhancements to improve the security and performance, accounting for clinical errors in the proposed scheme. Authors in [102] proposed a uniquely collaborative and intelligent security model for the IoT-based healthcare environment. The main objectives are to reduce security risks posed to a diverse range of IoT-enabled healthcare solutions. The proposed system is designed with a particular emphasis on the recent advances in this field. Various ML techniques are used for secured classification of the patient data. Likewise, authors in [103] presented a WBSN-enabled IoT healthcare solution. The proposed approach monitors the patient using wireless body network that consists of tiny, lightweight sensor nodes. The proposed approach uses various ML techniques to ensure that security is enhanced by protecting WBSN from intruders and various attacks. In [104], the authors proposed a novel mobile cloud computing framework for big data analytics. The main features of the proposed framework are that it offers availability and interoperability of health-care data, which can be shared among all interested parties. Various ML and DL techniques were used for classifying and testing the gathered data from patients. Although privacy and security of the health-care data are thoroughly discussed, they were not evaluated practically. In Table 6 , we have shown various ML-based secured analysis approaches for smart healthcare. 
Table 5 ML-based Assisted Living Techniques for Smart Healthcare

\begin{tabular}{|c|c|c|c|c|}
\hline Description & Feature & Category & Strengths & Weaknesses \\
\hline $\begin{array}{l}\text { Alert-based Cloud-connected } \\
\text { monitoring system [95] }\end{array}$ & $\begin{array}{l}\text { Elderly patient } \\
\text { assistance }\end{array}$ & $\begin{array}{r}\text { Assisted } \\
\text { living }\end{array}$ & $\begin{array}{l}\text { Performance, life } \\
\text { time }\end{array}$ & $\begin{array}{l}\text { Limited } \\
\text { functionalities, } \\
\text { Connectivity, }\end{array}$ \\
\hline $\begin{array}{l}\text { Medicine-tracking } \\
\text { alarm-based patient moni- } \\
\text { toring system [96] }\end{array}$ & Medicine intake & $\begin{array}{r}\text { Assisted } \\
\text { living }\end{array}$ & Energy-efficiency & Quality of Service \\
\hline $\begin{array}{l}\text { Real-time monitoring system } \\
\text { for dynamic changes in the } \\
\text { pre-defined health condi- } \\
\text { tions [97] }\end{array}$ & $\begin{array}{l}\text { Healthcare } \\
\text { monitoring system } \\
\text { for patients in the } \\
\text { ICU }\end{array}$ & $\begin{array}{r}\text { Assisted } \\
\text { living }\end{array}$ & $\begin{array}{l}\text { Efficient, } \\
\text { Accuracy }\end{array}$ & $\begin{array}{l}\text { Availability, Load } \\
\text { balancing }\end{array}$ \\
\hline $\begin{array}{l}\text { Intelligent monitoring system } \\
\text { for patients based on their } \\
\text { movement. [98] }\end{array}$ & Motion-awareness & $\begin{array}{r}\text { Assisted } \\
\text { living }\end{array}$ & Energy-efficient & Noise, Error \\
\hline $\begin{array}{l}\text { ML-based patient monitoring } \\
\text { system [99] }\end{array}$ & $\begin{array}{l}\text { Human presence } \\
\text { detection without } \\
\text { cameras and } \\
\text { motion detectors }\end{array}$ & $\begin{array}{r}\text { Assisted } \\
\text { living }\end{array}$ & $\begin{array}{l}\text { Feasible, } \\
\text { Inexpensive }\end{array}$ & $\begin{array}{l}\text { Precision, } \\
\text { Performance, } \\
\text { Interoperability }\end{array}$ \\
\hline $\begin{array}{l}\text { Arduino-based real-time } \\
\text { monitoring system [100] }\end{array}$ & $\begin{array}{l}\text { Lightweight, } \\
\text { real-time patient } \\
\text { health monitoring }\end{array}$ & $\begin{array}{r}\text { Assisted } \\
\text { living }\end{array}$ & $\begin{array}{l}\text { Inexpensive, } \\
\text { Simple }\end{array}$ & $\begin{array}{l}\text { Real time, Single } \\
\text { subject, Low } \\
\text { accuracy }\end{array}$ \\
\hline
\end{tabular}

\section{Challenges and open research issues}

In this section, we provide an insight into various challenges related to ML techniques for big data analytics in the IoT healthcare domain, as shown in Fig. 5. Moreover, research gaps are also provided for researchers to fill them in the future.

\subsection{Resource scarcity}

In IoT, most devices such as sensors, smart phones, microcontrollers actuators, RFIDs, and gateways have limited energy with lower computational and processing power [105-107]. Moreover, data generated from these densely deployed, resource-starved devices contain similar and redundant patterns. Transmitting such correlated data across the network results in high energy consumption, lower QoS and lower throughput $[108,109]$. The resource limitation issue is resolved upto some extent by integrating the IoT with the cloud computing paradigm. However, it increases the cost and complexity. Besides, other issues related to resource management such as resource discovery, modeling, provisioning, scheduling, estimation and monitoring are still of higher concern due to the unique nature of IoT networks [110]. Furthermore, optimization within the resource allocation techniques is an area to be explored further in this context. It is compulsory to design novel, lightweight and energy-efficient data aggregation techniques based on ML, as most of the
Table 6 ML-based Secured Analysis for Smart Healthcare

\begin{tabular}{|c|c|c|c|c|}
\hline Description & Features & Type & Strengths & Weaknesses \\
\hline $\begin{array}{l}\text { IoT-based real-time monitoring } \\
\text { system using watermarking } \\
\text { and signal enhancements [101] }\end{array}$ & $\begin{array}{l}\text { Resilient for clinical } \\
\text { errors detection }\end{array}$ & $\begin{array}{l}\text { Secured } \\
\text { Anal- } \\
\text { ysis }\end{array}$ & $\begin{array}{l}\text { Security, } \\
\text { Accuracy, } \\
\text { QoS }\end{array}$ & $\begin{array}{l}\text { Security } \\
\text { Optimization, } \\
\text { Implementing } \\
\text { and testing on } \\
\text { real world } \\
\text { patients }\end{array}$ \\
\hline $\begin{array}{l}\text { Collaborative and intelligent } \\
\text { security model for IoT-enabled } \\
\text { health care [102] }\end{array}$ & $\begin{array}{l}\text { Ensures the privacy and } \\
\text { security of healthcare } \\
\text { data }\end{array}$ & $\begin{array}{l}\text { Secured } \\
\text { Anal- } \\
\text { ysis }\end{array}$ & $\begin{array}{l}\text { Lightweight, } \\
\text { Secured }\end{array}$ & Fault tolerance, \\
\hline $\begin{array}{c}\text { Wireless Body Sensor Network } \\
\text { WBSN)-enabled intelligent } \\
\text { monitoring system [103] }\end{array}$ & $\begin{array}{l}\text { Protect the healthcare } \\
\text { system from } \\
\text { Intruders }\end{array}$ & $\begin{array}{l}\text { Secured } \\
\text { Anal- } \\
\text { ysis }\end{array}$ & $\begin{array}{l}\text { Security, } \\
\text { Efficiency }\end{array}$ & $\begin{array}{l}\text { Performance, } \\
\text { Energy- } \\
\text { efficiency }\end{array}$ \\
\hline $\begin{array}{l}\text { Mobile CloudComputing (MCC) } \\
\text { framework [104] }\end{array}$ & $\begin{array}{l}\text { Big data analytics for } \\
\text { availability \& } \\
\text { interoperability of } \\
\text { health data }\end{array}$ & $\begin{array}{l}\text { Secured } \\
\text { Anal- } \\
\text { ysis }\end{array}$ & $\begin{array}{l}\text { Availability, } \\
\text { Interoper- } \\
\text { able }\end{array}$ & $\begin{array}{c}\text { Performance, } \\
\text { Accuracy }\end{array}$ \\
\hline
\end{tabular}


Fig. 5 Challenges faced by ML techniques for big data analytics for IoT healthcare

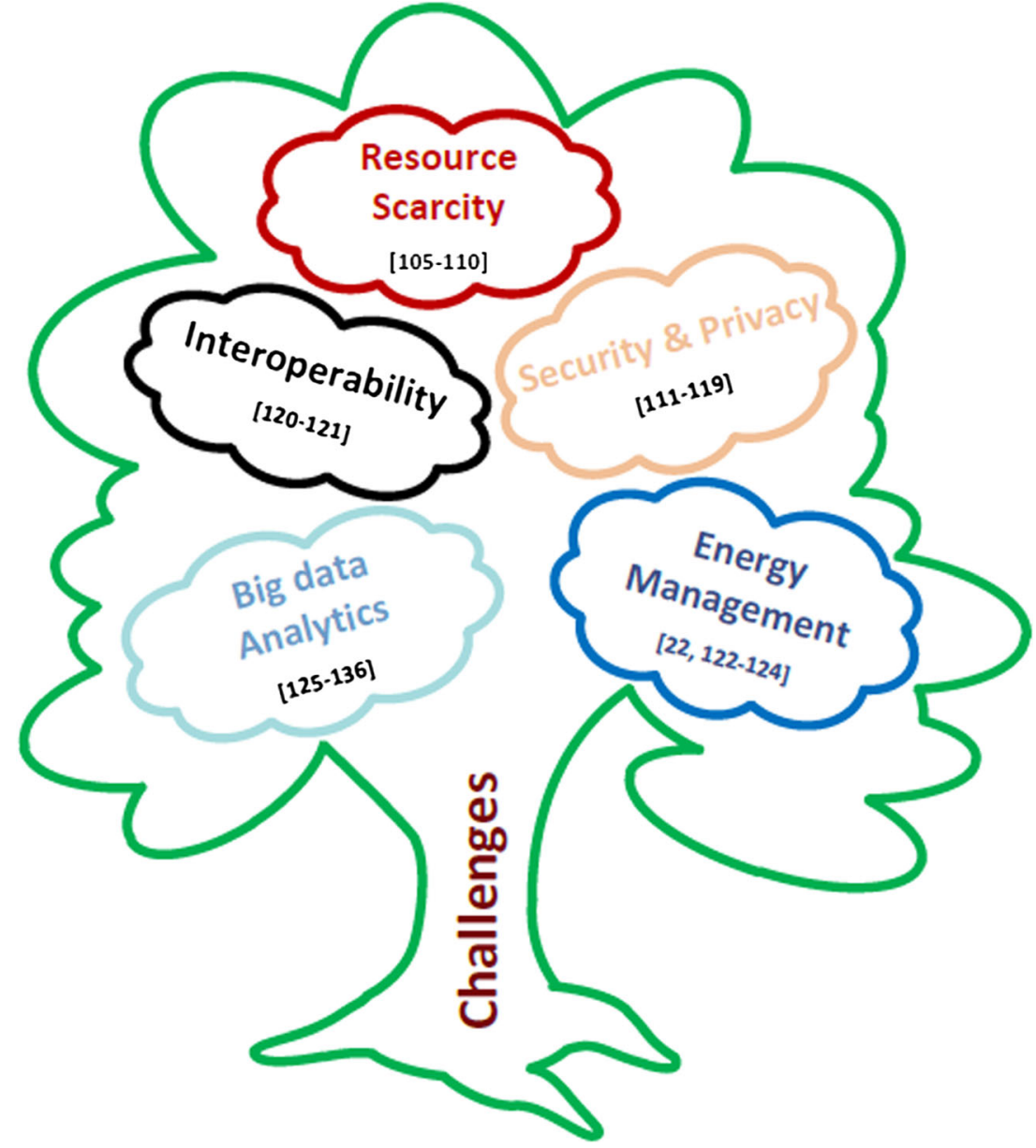

existing techniques are not energy-efficient. Moreover, novel schemes should be devised that distribute the task among various IoT components that not only matches the resource scarcity of these networks, but also offers an acceptable level of accuracy [105].

\subsection{Security and privacy}

The application of IoT in healthcare domain is providing personalized facilities, i.e., customized and rapid access to healthcare which was unimaginable earlier. In these applications, both the technology and healthcare devices work with each other to offer a wide range of services. It is forecasted that almost $40 \%$ of IoT-related technology will be health-related shortly, more than any other market segment, with a huge market share of USD 136.8 billion by 2021 in [111]. Such developments in this field are revolutionary, however, it should be carefully adopted due to the challenges faced in the context of security, privacy and sensitivity by healthrelated data [112-114]. Upstream transmission of compromised data not only has a devastating effect on the underlying data aggregation technique but also deteriorates its performance [115]. It exposes the underlying networks to a wide range of security attacks such as DoS, eavesdropping, Sybil, sinkhole, and sleep deprivation attacks. These threats remain a challenge due to the rapid expansion in the field with an everincreasing number and complexity of the emerging software and hardware vulnerabilities. Besides, healthcare data containing sensitive and confidential information such as personal details, family history, electronic medical records, and genomic data should be kept confidential. It was predicted that $72 \%$ of malicious traffic targeted the healthcare data [116]. It is thus imperative to protect such data from hackers by enforcing privacy and security, both physically and virtually [117]. Other challenges include low security, misconfigured devices, and network settings. Moreover, data from these varying range of devices are mostly heterogeneous in nature and usually managed by third parties and thus governance, security, and privacy of such data become a challenging task [118, 119]. Furthermore, existing security techniques are not a feasible option due to the resourceconstrained nature of IoT devices. Designing lightweight and energy-efficient data aggregation techniques that not only secure, but also ensure the confidentiality, security and privacy of the data is an interesting domain for further examination. 


\subsection{Interoperability}

Recently, we have witnessed rapid development both in the hardware and software but the actual challenge is the lack of global standards that are accepted and agreed by public across the globe. Thus, the healthcare IoT devices pose serious interoperability challenges. The designer must not only focus on the development side but at the same time, strive for interoperability among all aspects of IoT eHealth such as smart wearables, body area sensors, and advanced pervasive healthcare to promote healthier life styles $[120,121]$. The benefits associated with interoperable devices are increased throughput, minimized unplanned outages, and reduced maintenance costs. Semantic interoperability of the clinical information is an important area for future research.

\subsection{Energy management}

Energy management is another challenging aspect of IoT healthcare applications. Usually, wearable and sensors attached to the human body are energy-constrained. They are equipped with limited energy supplies [122]. The frequent changes of batteries in these sensors and devices is cumbersome and sometimes impossible. Supplementary healthcare professionals with additional costs will be required to constantly look after these devices and sensors for battery replacement, whenever energy goes beyond certain thresholds. This will result in fatigue and mismanagement due to dynamic environments. Energy efficiency becomes an integral factor that determines the success of the underlying applications [22]. To overcome and improve energy conservation, it is necessary to design low power sensors that do not require frequent changes of batteries while, providing a reliable supply of power at the same time. Moreover, energy optimization algorithms with smarter energy management techniques have seen little attention and therefore need serious consideration from the researchers in IoT healthcare sector [123, 124]. Another area of research is the optimization of routing approaches that exploit the correlation among the captured data before it reaches its final destination, i.e., data aggregation techniques. These techniques eliminate redundancy that lowers the communication cost, conserves the energy and enhances the network lifetime.

\subsection{Big data analytics}

Another challenging aspect of IoT healthcare is big data analytics that deals with large-scale unstructured data. Recently, we have witnessed significant developments in hardware, software, and a diverse range of innovative IoT applications. Moreover, the growth forecast of IoT in the future is even more exaggerated with a large number of interconnected data sources and platforms with global infrastructure for information and communication. As a result, huge amount of data is produced. This large volume of mostly redundant data is transmitted across the network for analysis and decision making. Transmitting such large volume of data across the network can adversely affect the network performance. This brings many challenging issues that need to be dealt with utmost care [125]. In this context, it would be interesting to see how to gain insight into this huge volume of data for better decision making and optimized operations using various $\mathrm{ML}$ and DL-enabled techniques [126]. It is imperative to design novel big data analytics tools and techniques that perform analysis and extract the required information. Innovative noise removal techniques are needed to enhance the data signal, improve the quality of aggregated data, and conserve the overall energy of the network [127]. More importantly, in healthcare applications, most of the devices perform realtime monitoring and analysis. It would be interesting to see novel ML techniques in the future that apply real-time analytics by monitoring current conditions and respond accordingly. Novel data aggregation techniques with outlier reduction should be devised with improve security, QoS and lowered computation complexity. Furthermore, data aggregation has a stronger relationship with the underlying topology of the network. The performance of these techniques are greatly affected by the underlying topologies [128-131]. In this regard, clustering tends to be more effective in static networks, where network configuration remains the same for longer time. However, they need to be studied in dynamic as well as heterogeneous environments [132-136]. Finding an optimal location for these devices should be further investigated so that IoT can cater for a wide range of emerging healthcare applications in the years ahead.

\section{Limitations and future work}

In this paper, we have presented a detailed survey of big data analytics in IoT health-care domain. We have thoroughly studied the literature and selected the most relevant and up to date surveys to find research gap. Furthermore, we have also provided a comprehensive and state-of-the-art literature on ML-based techniques for big data analytics in IoT smart health. A detailed discussion of their strengths and weakness was also provided. This provided an insight to the readers in this domain and enable them to start their research by selecting the topic of their choice from available pool of techniques. Various research issues and challenges were discussed that motivate the researchers to exploit them further. Moreover, various issues that raised due to the emerging and crossdomain architectures of IoT, i.e., Internet of Nano-Things (IoNT), and web of Things (WoT) were thoroughly discussed to make a universal IoT vision a reality, a vision that 
successfully integrates this technology in almost all domains and that will hopefully flourish our daily lives in the years to come.

Authors' contributions This paper is equally contributed by each author as everyone wrote a section of it. Besides, there was collaborative efforts in brainstorming the idea of this paper, proofread and formatting of this paper.

Data availability Not applicable.

\section{Compliance with ethical standards}

Conflicts of interest/competing interests The authors declare that they have no conflict of interest.

Code availability Not applicable.

\section{References}

1. Evtodieva TE, Chernova DV, Ivanova NV, Wirth J (2020) The internet of things: possibilities of application in intelligent supply chain management. In: Digital Transformation of the Economy: Challenges, Trends and New Opportunities. Springer, Cham, pp 395-403

2. Abdollahzadeh S, Navimipour NJ (2016) Deployment strategies in the wireless sensor network: A comprehensive review. Computer Communications 91:1-16

3. Piccialli F, Jung JE (2017) Understanding customer experience diffusion on social networking services by big data analytics. Mobile Networks and Applications 22(4):605-612

4. Joe S (2014) Qin. Process data analytics in the era of big data. AICHE Journal 60(9):3092-3100

5. Baker SB, Xiang W, Atkinson I (2017) Internet of things for smart healthcare: Technologies, challenges, and opportunities. IEEE Access 5:26521-26544

6. Latif S, Afzaal H, Zafar NA (2018) Intelligent traffic monitoring and guidance system for smart city. In: International Conference on Computing, Mathematics and Engineering Technologies (iCoMET). IEEE, pp 1-6

7. Babar M, Khan F, Iqbal W, Yahya A, Arif F, Tan Z, Chuma JM (2018) A secured data management scheme for smart societies in industrial internet of things environment. IEEE Access 6:4308843099

8. Pouryazdan M, Fiandrino C, Kantarci B, Soyata T, Kliazovich D, Bouvry P (2017) Intelligent gaming for mobile crowd-sensing participants to acquire trustworthy big data in the internet of things. IEEE Access 5:22209-22223

9. Liu J, Shen H, Narman HS, Chung W, Lin Z (2018) A survey of mobile crowd sensing techniques: A critical component for the internet of things. ACM Transactions on Cyber- Physical Systems 2(3):1-26

10. Lashkari B, Rezazadeh J, Farahbakhsh R, Sandrasegaran K (2018) Crowdsourcing and sensing for indoor localization in IoT: A review. IEEE Sensors Journal 19(7):2408-2434

11. Dehkordi SA, Farajzadeh K, Rezazadeh J, Farahbakhsh R, Sandrasegaran K, Dehkordi MA (2020) A survey on data aggregation techniques in IoT sensor networks. Wireless Networks 26(2):1243-1263

12. Rodríguez-Mazahua L, Rodríguez-Enríquez C-A (2016) José Luis Sánchez-Cervantes, Jair Cervantes, Jorge Luis García- Alcaraz, and Giner Alor-Hernández. A general perspective of big data: applications, tools, challenges and trends. The Journal of Supercomputing 72(8):3073-3113

13. Hashem IAT, Yaqoob I (2015) Nor Badrul Anuar, Salima Mokhtar, Abdullah Gani, and Samee Ullah Khan. The rise of "bi data" on cloud computing: Review and open research issues. Information systems 47:98-115

14. Tsai C-W, Lai C-F, Chao H-C, Vasilakos A (2015) Big data analytics: a survey. Journal of Big data 2(1):21

15. Athey $S$ (2018) The impact of machine learning on economics. In: The economics of artificial intelligence: An agenda. University of Chicago Press, pp 507-547

16. Mohammadi M, Al-Fuqaha A, Sorour S, Guizani M (2018) Deep learning for iot big data and streaming analytics: A survey. IEEE Communications Surveys \& Tutorials 20(4):2923-2960

17. Cui L, Yang S, Chen F, Ming Z, Lu N, Qin J (2018) A survey on application of machine learning for internet of things. International Journal of Machine Learning and Cybernetics 9(8):1399-1417

18. Ge M, Bangui H, Buhnova B (2018) Big data for internet of things: a survey. Future Generation Computer Systems 87:601614

19. Mahdavinejad MS, Rezvan M, Barekatain M, Adibi P, Barnaghi P, Sheth AP (2018) Machine learning for internet of things data analysis: A survey. Digital Communications and Networks 4(3): $161-175$

20. Firouzi F, Rahmani AM, Mankodiya K, Badaroglu M, Merrett GV, Wong P, Farahani B (2018) Internet-of-Things and big data for smarter healthcare: From device to architecture, applications and analytics. Future Generation Computer Systems 78:583-586

21. Pourghebleh B, Navimipour NJ (2017) Data aggregation mechanisms in the internet of things: A systematic review of the literature and recommendations for future research. Journal of Network and Computer Applications 97:23-34

22. Dehkordi SA, Farajzadeh K, Rezazadeh J, Farahbakhsh R, Sandrasegaran K, Dehkordi MA (2020) A survey on data aggregation techniques in IoT sensor networks. Springer Wireless Networks 26(2):1243-1263

23. Olaković AČ, Hadžialić M (2018) Internet of things (IoT): A review of enabling technologies, challenges, and open research issues. Computer Networks 144:17-39

24. Boubiche S, Boubiche DE, Bilami A, Toral-Cruz H (2018) Big data challenges and data aggregation strategies in wireless sensor networks. IEEE Access 6:20558-20571

25. Ghate VV, Vijayakumar V (2018) Machine learning for data aggregation in wsn: A survey. International Journal of Pure and Applied Mathematics 118(24):1-12

26. Al-Fuqaha A, Guizani M, Mohammadi M, Aledhari M, Ayyash M (2015) Internet of things: A survey on enabling technologies, protocols, and applications. IEEE communications surveys \& tutorials 17(4):2347-2376

27. Lee I, Lee K (2015) The internet of things (IoT): Applications, investments, and challenges for enterprises. Business Horizons 58(4):431-440

28. Shirvanimoghaddam M, Dohler M, Johnson SJ (2017) Massive non-orthogonal multiple access for cellular IoT: Potentials and limitations. IEEE Communications Magazine 55(9):55-61

29. Aggarwal M, Saxena N, Roy A (2019) Towards connected living: $5 \mathrm{~g}$ enabled internet of things (IoT). IETE Technical Review 36(2): 190-202

30. Ghose A, Pal A, Choudhury AD, Chattopadhyay T, Bhowmick PK, Chattopadhyay D (2014) "Internet of things (iot) application development." U.S. Patent Application 14/286,068, filed November 27, 2014

31. Yang C,Shen W, Wang X (2016) Applications of internet of things in manufacturing. IEEE $20^{\text {th }}$ International Conference on 
Computer Supported Cooperative Work in Design (CSCWD). IEEE 670-675

32. Ansari S, Aslam T, Poncela J, Otero P, Ansari A (2020) Internet of Things-Based Healthcare Applications. In: IoT Architectures, Models, and Platforms for Smart City Applications. IGI Global, pp 1-28

33. Shah S, Ververi A (2018) Evaluation of Internet of Things (IoT) and its Impacts on Global Supply Chains. In: 2018 IEEE International Conference on Technology Management, Operations and Decisions (ICTMOD). IEEE, pp 160-165

34. Enginkaya E, Akgül AK (2018) The consumers'life simlifiers: Innovative developments and transformations. Business Studies 83

35. Alkhayyat A, Thabit AA, Al-Mayali FA, Abbasi QH (2019) WBSN in IoT health-based application: toward delay and energy consumption minimization. Journal of Sensors, Hindawi

36. Nguyen HH, Mirza F, Naeem MA, Nguyen M (2017) A review on IoT healthcare monitoring applications and a vision for transforming sensor data into real-time clinical feedback. In: 2017 IEEE $21^{\text {st }}$ International Conference on Computer Supported Cooperative Work in Design (CSCWD). IEEE, pp 257-262

37. Abdullah A, Ismael A, Rashid A, Abou-ElNour A, Tarique M (2015) Real time wireless health monitoring application using mobile devices. International Journal of Computer Networks \& Communications (IJCNC) 7(3):13-30

38. Yuehong YIN, Zeng Y, Chen X, Fan Y (2016) The internet of things in healthcare: An overview. Journal of Industrial Information Integration 1:3-13

39. Ramathulasi T, Rajasekhara Babu M (2020) Comprehensive Survey of IoT Communication Technologies. In: Emerging Research in Data Engineering Systems and Computer Communications. Springer, Singapore, pp 303-311

40. Al-Garadi MA, Mohamed A, Al-Ali A, Du X, Ali I, Guizani M (2020) A survey of machine and deep learning methods for internet of things (IoT) security. IEEE Communications Surveys \& Tutorials

41. Shah JL, Bhat HF (2020) CloudIoT for Smart Healthcare: Architecture, Issues, and Challenges. In: Internet of Things Use Cases for the Healthcare Industry. Springer, Cham, pp 87-126

42. Aman W, Khan F (2019) Ontology-based Dynamic and Contextaware Security Assessment Automation for Critical Applications. In: the IEEE $8^{\text {th }}$ Global Conference on Consumer Electronics (GCCE). IEEE, pp 644-647, Japan

43. Jayaraman PP, Perera C, Georgakopoulos D, Dustdar S, Thakker D, Ranjan R (2017) Analyticsas- a-service in a multi-cloud environment through semantically-enabled hierarchical data processing. Software: Practice and Experience 47(8):1139-1156

44. Pflanzner T, Kertész A (2016) A survey of iot cloud providers. Croatian Society for Information and Communication Technology Electronics 730-735

45. Ray PP (2016) A survey of iot cloud platforms. Future Computing and Informatics Journal 1(1-2):35-46

46. Khan F, Yahya A, Jan MA, Chuma J, Tan Z, Hussain K (2019) A Quality of Service-Aware Secured Communication Scheme for Internet of Things-Based Networks. MDPI Sensors 19(19):4321

47. Bowya M, Karthikeyan V (2020) A Novel Secure IoT Based Optimizing Sensor Network for Automatic Medicine Composition Prescribe System. In: Inventive Communication and Computational Technologies. Springer, Singapore, pp $1109-1118$

48. Qian B, Jie S, Wen Z, Jha DN, Li Y, Guan Y, Puthal D et al (2020) Orchestrating the development lifecycle of machine learningbased iot applications: A taxonomy and survey. ACM Computing Surveys (CSUR) 53(4):1-47
49. Babu GC, Shantharajah SP (2018) Survey on data analytics techniques in healthcare using IoT platform. International Journal of Reasoning-based Intelligent Systems 10(3-4):183-196

50. Jagadeeswari V, Subramaniyaswamy V, Logesh R, Vijayakumar VJHIS (2018) A study on medical internet of things and big data in personalized healthcare system. Health information science and systems 6(1):14

51. Elhayatmy G, Dey N, Ashour AS (2018) Internet of Things based wireless body area network in healthcare. In: Internet of things and big data analytics toward next-generation intelligence. Springer, Cham, pp 3-20

52. Wang Y, Kung LA, Byrd TA (2018) Big data analytics: Understanding its capabilities and potential benefits for healthcare organizations. Technological Forecasting and Social Change 126: $3-13$

53. Vassakis K, Petrakis E, Kopanakis I (2018) Big data analytics: applications, prospects and challenges. In: Mobile big data. Springer, Cham, pp 3-20

54. Huang X-L, Ma X, Hu F (2018) Machine learning and intelligent communications. Mobile Networks and Applications 23(1):68-70

55. Khattak MI, Edwards RM, Shafi M, Ahmed S, Shaikh R, Khan F (2018) "Wet environmental conditions affecting narrow band onbody communication channel for WBANs." 40, 297-312

56. Kremer J, Stensbo-Smidt K, Gieseke F, Pedersen KS, Igel C (2017) Big universe, big data: machine learning and image analysis for astronomy. IEEE Intelligent Systems 32(2):16-22

57. Choo J, Liu S (2018) Visual analytics for explainable deep learning. IEEE computer graphics and applications 38(4):84-92

58. Young T, Hazarika D, Poria S, Cambria E (2018) Recent trends in deep learning based natural language processing. IEEE Computational intelligence magazine 13(3):55-75

59. Nassif AB, Shahin I, Attili I, Azzeh M, Shaalan K (2019) Speech recognition using deep neural networks: A systematic review. IEEE Access 7:19143-19165

60. Ayoubi S, Limam N, Salahuddin MA, Shahriar N, Boutaba R, Estrada-Solano F, Caicedo OM (2018) Machine learning for cognitive network management. IEEE Communications Magazine 56(1):158-165

61. Sheikhnejad Y, Gonçalves D, Oliveira M, Martins N (2020) Can buildings be more intelligent than users?-the role of intelligent supervision concept integrated into building predictive control. Energy Reports 6:409-416

62. Chen H, Chiang RHL, Storey VC (2012) Business intelligence and analytics: From big data to big impact. MIS quarterly, $1165-1188$

63. Karim A, Siddiqa A, Safdar Z, Razzaq M, Gillani SA, Tahir H, Kiran S, Ahmed E, Imran M (2020) Big data management in participatory sensing: Issues, trends and future directions. Future Generation Computer Systems 107:942-955

64. Diène B, Rodrigues JJPC, Diallo O, Ndoye ELHM, Korotaev VV (2020) Data management techniques for internet of things. Mechanical Systems and Signal Processing 138:106564

65. Firouzi F, Farahani B, Weinberger M, DePace G, Aliee FS (2020) IoT Fundamentals: Definitions, Architectures, Challenges, and Promises. In: Intelligent Internet of Things. Springer, Cham, pp $3-50$

66. Farahani, Bahar, Farshad Firouzi, and Krishnendu Chakrabarty. "Healthcare iot." In Intelligent Internet of Things, pp. 515-545. Springer, Cham, 2020.

67. Malakis S, Psaros P, Kontogiannis T, Malaki C (2020) Classification of air tra c control scenarios using decision trees: insights from a field study in terminal approach radar environment. Cognition, Technology \& Work 22(1):159-179

68. Lee S, Kim Y, Kahng H, Lee S-K, Chung S, Cheong T, Shin K, Park J, Kim SB (2020) Intelligent tra_c control for autonomous 
vehicle systems based on machine learning. Expert Systems with Applications 144:113074

69. Crane-Droesch A (2018) Machine learning methods for crop yield prediction and climate change impact assessment in agriculture. Environmental Research Letters 13(11):114003

70. Stupar S, Ćar MB, Kurtović E, Vico G (2020) Theoretical and Practical Aspects of Internet of Things (IoT) Technology. In: International Conference "New Technologies, Development and Applications". Springer, Cham, pp 422-431

71. Alsharif MH, Kelechi AH, Yahya K, Chaudhry SA (2020) Machine learning algorithms for smart data analysis in internet of things environment: taxonomies and research trends. Symmetry 12(1):88

72. Obermeyer Z, Emanuel EJ (2016) Predicting the Future-Big Data, Machine Learning, and Clinical Medicine. New England Journal of Medicine 375(13):1216-1219

73. Ker J, Wang L, Rao J, Lim T (2017) Deep learning applications in medical image analysis. Ieee Access 6:9375-9389

74. Dantu R, Dissanayake I, Nerur S (2020) Exploratory Analysis of Internet of Things (IoT) in Healthcare: A Topic Modelling \& Cocitation Approaches. In: Information Systems Management. Taylor $\backslash \&$ Francis, pp 1-17

75. Mehta N, Pandit A, Kulkarni M (2020) Elements of healthcare big data analytics. In: Big Data Analytics in Healthcare. Springer, p 23

76. Balakrishna S, Thirumaran M, Solanki VK (2020) IoT sensor data integration in healthcare using semantics and machine learning approaches. In: A Handbook of Internet of Things in Biomedical and Cyber Physical System. Springer, Cham, pp 275-300

77. Asthana S, Megahed A, Strong R (2017) A recommendation system for proactive health monitoring using IoT and wearable technologies. In: 2017 IEEE International Conference on AI \& Mobile Services (AIMS). IEEE, pp 14-21

78. Yao W, Yahya A, Khan F, Tan Z, Rehman AU, Chuma JM, Jan MA, Babar M (2019) A secured and efficient communication scheme for decentralized cognitive radio-based Internet of vehicles. the IEEE Access 7:160889-160900

79. Moosavi SR, Gia TN, Rahmani A-M, Nigussie E, Virtanen S, Isoaho J, Tenhunen H (2015) SEA: A Secure and Efficient Authentication and Authorization Architecture for IoT-Based Healthcare Using Smart Gateways. Procedia Computer Science $52: 452-459$

80. Subramaniyaswamy V, Manogaran G, Logesh R, Vijayakumar V, Chilamkurti N, Malathi D, Senthilselvan N (2019) An ontologydriven personalized food recommendation in IoT-based healthcare system. The Journal of Supercomputing 75(6):3184-3216

81. Ali F, Islam SMR, Kwak D, Khan P, Ullah N, Yoo S-j, Kwak KS (2018) Type-2 fuzzy ontology-aided recommendation systems for iot-based healthcare. Computer Communications 119:138-155

82. Khan F, Rehman AU, Zheng J, Jan MA, Alam M (2019) Mobile crowdsensing: A survey on privacy-preservation, task management, assignment models, and incentives mechanisms. Future Generation Computer Systems 100:456-472

83. Borthakur D, Dubey H, Constant N, Mahler L, Mankodiya K (2017) Smart fog: Fog computing framework for unsupervised clustering analytics in wearable internet of things. In: 2017 IEEE Global Conference on Signal and Information Processing (GlobalSIP). IEEE, pp 472-476

84. Verma P, Sood SK (2019) A comprehensive framework for student stress monitoring in fog-cloud IoT environment: m-health perspective. Medical \& biological engineering \& computing 57(1):231-244

85. Rahmani AM, Gia TN, Negash B, Anzanpour A, Azimi I, Jiang M, Liljeberg P (2018) Exploiting smart e-health gateways at the edge of healthcare internet-of-things: A fog computing approach. Future Generation Computer Systems 78:641-658
86. Kumar PM, Gandhi UD (2018) A novel three tier internet of things architecture with machine learning algorithm for early detection of heart diseases. Computers \& Electrical Engineering 65: 222-235

87. Gelogo YE, Oh J-W, Park JW, Kim H-K (2015) Internet of things (IoT) driven u-healthcare system architecture. $8^{\text {th }}$ International Conference on Bio-Science and Bio-Technology (BSBT), 24-26

88. Azimi I, Anzanpour A, Rahmani AM, Pahikkala T, Levorato M, Liljeberg P, Dutt N (2017) Hich: Hierarchical fog assisted computing architecture for healthcare IoT. ACM Transactions on Embedded Computing Systems (TECS) 16(5):1-20

89. Kirtana RN, Lokeswari YV (2017) An IoT based remote HRV monitoring system for hypertensive patients. In: 2017 International Conference on Computer, Communication and Signal Processing (ICCCSP). IEEE, pp 1-6

90. Ganapathy K, Sethukkarasi R, Yogesh P, Vijayakumar P, Kannan A (2014) An intelligent temporal pattern classification system using fuzzy temporal rules and particle swarm optimization. Sadhana 39(2):283-302

91. Alsheikh MA, Lin S, Niyato D, Tan H-P (2016) Rate-distortion balanced data compression for wireless sensor networks. IEEE Sensors Journal 16(12):5072-5083

92. Qiu T, Liu X, Lin F, Yu Z, Zheng K (2016) An efficient tree-based self-organizing protocol for internet of things. IEEE Access 4: 3535-3546

93. Khan F, Rehman AU, Jan MA, Rahman IU (2019) Efficient resource allocation for real time traffic in cognitive radio internet of things. In: In the International Conference on Internet of Things (iThings). IEEE, pp 1143-1147

94. Fang R, Pouyanfar S, Yang Y, Chen S-C, Iyengar SS (2016) Computational health informatics in the big data age: a survey. ACM Computing Surveys (CSUR) 49(1):1-36

95. Pinto S, Cabral J, Gomes T (2017) We-care: An IoT-based health care system for elderly people. In: 2017 IEEE International Conference on Industrial Technology (ICIT). IEEE, pp 13781383

96. Li J, Cai J, Khan F, Rehman AU, Balasubramaniam V, Sun J, Venu P (2020) A Secured Framework for SDN-Based Edge Computing in IoT-Enabled Healthcare System. IEEE Access 8: 135479-135490

97. Prajapati B, Parikh S, Patel J (2017) An Intelligent Real Time IoT Based System (IRTBS) for Monitoring ICU Patient. In: International Conference on Information and Communication Technology for Intelligent Systems. Springer, Cham, pp 390-396

98. Kim S-H, Chung K (2015) Emergency situation monitoring service using context motion tracking of chronic disease patients. Cluster Computing, Springer 18(2):747-759

99. Jan MA, Zhang W, Usman M, Tan Z, Khan F, Luo E (2019) SmartEdge: An end-to-end encryption framework for an edgeenabled smart city application. Journal of Network and Computer Applications 137:1-10

100. Vippalapalli V, Ananthula S (2016) Internet of things (IoT) based smart health care system. In: 2016 International Conference on Signal Processing, Communication, Power and Embedded System (SCOPES). IEEE, pp 1229-1233

101. Khan F, Jan MA, Rehman A u, Mastorakis S, Alazab M, Watters P (2020) "A Secured and Intelligent Communication Scheme for IIoT-enabled Pervasive Edge Computing", in IEEE Transaction on Industrial Informatics. Early Access

102. Khan F, Rehman A u, Usman M, Tan Z, Puthal D (2018) Performance of cognitive radio sensor networks using hybrid automatic repeat ReQuest: Stop-and-wait. Mobile Networks and Applications 23(3):479-488

103. Gope P, Hwang T (2015) Bsn-care: A secure IoT-based modern healthcare system using body sensor network. IEEE sensors journal 16(5):1368-1376 
104. Essa YM, Attiya G, El-Sayed A, ElMahalawy A (2018) Data processing platforms for electronic health records. Health and Technology 8(4):271-280

105. Khan IH, Khan MI, Khan S (2020) Challenges of IoT Implementation in Smart City Development. In: Smart CitiesOpportunities and Challenges. Springer, Singapore, pp 475-486

106. Ishtiaq M, Rehman AU, Khan F, Salam A (2019) Performance Investigation of SR-HARQ transmission scheme in realistic Cognitive Radio System. In: the IEEE $9^{\text {th }}$ Annual Computing and Communication Workshop and Conference (CCWC). IEEE, pp 0258-0263

107. Hussain F, Hassan SA, Hussain R, Hossain E (2020) Machine learning for resource management in cellular and IoT networks: Potentials, current solutions, and open challenges. IEEE Communications Surveys \& Tutorials 22(2):1251-1275

108. Naha RK, Garg S, Chan A, Battula SK (2020) Deadline-based dynamic resource allocation and provisioning algorithms in fogcloud environment. Future Generation Computer Systems 104: 131-141

109. Zhou J, Cao Z, Dong X, Vasilakos AV (2017) Security and privacy for cloud-based IoT: Challenges. IEEE Communications Magazine 55(1):26-33

110. Ali SA, Ansari M, Alam M (2020) Resource Management Techniques for Cloud-Based IoT Environment. In: Internet of Things (IoT). Springer, Cham, pp 63-87

111. Marr B (2018) Why the internet of medical things (IoMT) will start to transform healthcare

112. Kaur H, Atif M, Chauhan R (2020) An Internet of Healthcare Things (IoHT)-Based Healthcare Monitoring System. In: Advances in Intelligent Computing and Communication. Springer, Singapore, pp 475-482

113. Almolhis N, Alashjaee AM, Duraibi S, Alqahtani F, Moussa AN (2020) The Security Issues in IoT-Cloud: A Review. In: 2020 16th IEEE International Colloquium on Signal Processing \& Its Applications (CSPA). IEEE, pp 191-196

114. Bansal S, Kumar D (2020) IoT Ecosystem: A Survey on Devices, Gateways, Operating Systems, Middleware and Communication. International Journal of Wireless Information Networks:1-25

115. Sharma D, Tripathi RC (2020) Performance of internet of things based healthcare secure services and its importance: Issue and challenges. Technical report, EasyChair

116. Jan MA, Khan F, Alam M, Usman M (2019) A payload-based mutual authentication scheme for Internet of Things. Future Generation Computer Systems 92:1028-1039

117. Bhattacharjya A, Zhong X, Wang J, Li X (2020) Present Scenarios of IoT Projects with Security Aspects Focused. In: Digital Twin Technologies and Smart Cities. Springer, Cham, pp 95-122

118. Flynn T, Grispos G, Glisson W, Mahoney W (2020) "Knock! Knock! Who is there? Investigating data leakage from a medical internet of things hijacking attack." In Proceedings of the 53rd Hawaii International Conference on System Sciences

119. Williams PAH, McCauley V (2016) Always connected: The security challenges of the healthcare Internet of Things. In: 2016 IEEE 3rd World Forum on Internet of Things (WF-IoT). IEEE, pp 30-35

120. Khan F (2014) Fairness and throughput improvement in multihop wireless ad hoc networks. In: the IEEE 27th Canadian Conference on Electrical and Computer Engineering (CCECE). IEEE, pp 1-6

121. Qadri YA, Nauman A, Zikria YB, Vasilakos AV, Kim SW (2020) The Future of Healthcare Internet of Things: A Survey of
Emerging Technologies. IEEE Communications Surveys \& Tutorials 22(2):1121-1167

122. Park J, Bhat G, Geyik CS, Ogras UY, Lee HG (2020) Energy per operation optimization for energy-harvesting wearable IoT devices, Multidisciplinary Digital Publishing Institute. Sensors 20(3):764

123. Selvaraj S, Sundaravaradhan S (2020) Challenges and opportunities in IoT healthcare systems: a systematic review. SN Applied Sciences 2(1): 139

124. Mittal M, Tanwar S, Agarwal B, Goyal LM (eds) (2019) Energy Conservation for IoT Devices: Concepts, Paradigms and Solutions, vol 206. Springer

125. Yang K, Shi Y, Zhou Y, Yang Z, Fu L, Chen W (2020) Federated machine learning for intelligent IoT via reconfigurable intelligent surface. arXiv preprint arXiv:2004.05843

126. Gill SS, Buyya R (2019) Bio-inspired algorithms for big data analytics: a survey, taxonomy, and open challenges. In: Big Data Analytics for Intelligent Healthcare Management. Academic Press, pp 1-17

127. Wan R, Xiong N, Hu Q, Wang H, Shang J (2019) Similarityaware data aggregation using fuzzy c-means approach for wireless sensor networks. EURASIP Journal on Wireless Communications and Networking 2019(1):59

128. Qi G, Wang H, Haner M, Weng C, Chen S, Zhu Z (2019) Convolutional neural network based detection and judgement of environmental obstacle in vehicle operation. CAAI Transactions on Intelligence Technology 4(2):80-91

129. Li X, Zhao M, Liu Y, Li L, Ding Z, Nallanathan A (2020) "Secrecy Analysis of Ambient Backscatter NOMA Systems under I/Q Imbalance ," IEEE Transactions on Vehicular Technology, accepted for publication, Jun. 2020

130. Wiens T (2019) Engine speed reduction for hydraulic machinery using predictive algorithms. International Journal of Hydromechatronics 2(1):16-31

131. Li X, Wang Q, Liu Y, Tsiftsis TA, Ding Z, Nallanathan A (2020) UAV-Aided Multi-Way NOMA Networks with Residual Hardware Impairments. In: IEEE Wireless Communications Letters

132. Shokri M, Tavakoli K (2019) A review on the artificial neural network approach to analysis and prediction of seismic damage in infrastructure. International Journal of Hydromechatronics 2(4): 178-196

133. Xue X, Lu J, Chen J (2019) Using NSGA-III for optimising biomedical ontology alignment. CAAI Transactions on Intelligence Technology 4(3): 135-141

134. Ma J (2019) Numerical modelling of underwater structural impact damage problems based on the material point method. International Journal of Hydromechatronics 2(4):99-110

135. Khan F, Rehman A u, Jan MA (2020) A secured and reliable communication scheme in cognitive hybrid ARQ-aided smart city. Computers \& Electrical Engineering 81:106502

136. Yu T, Wang J, Wu L, Xu Y (2019) Three-stage network for age estimation. CAAI Transactions on Intelligence Technology 4(2): $122-126$

Publisher's note Springer Nature remains neutral with regard to jurisdictional claims in published maps and institutional affiliations. 